\title{
ESTIMATION OF MORTALITY RATE OF QSOFA AND SIRS
}

\section{DR. RAMESH M $M^{1}$, DR. IRSHAD AHMED ${ }^{2} \&$ DR. PRAKASHBABU $S^{3}$}

${ }^{I}$ Associate Professor, Department of Emergency Medicine, PESIMSR, Kuppam, Andhra Pradesh, India

${ }^{2}$ Senior Resident, Department of Emergency Medicine, PESIMSR ,Kuppam, Andhra Pradesh, India

${ }^{3}$ Assistant Professor, Department of Emergency Medicine, PESIMSR ,Kuppam, Andhra Pradesh, India

\begin{abstract}
\section{INTRODUCTION}

In Medical science, sepsis syndrome is characterized signs of infection and manifestation in relation with host response .As per the literature, it is the primary cause of mortality morbidity from infection enlisted in Medical emergency. The clear definition of sepsis has been varied throughout the preceding decades.An intervention of Sepsis is currently described life threatening organ dysfunction, represented by increase of lease two or more points in the Sequential Organ Assessment (SOFA) score. In Indian context, a very limited number of research papers cited to address research gap for estimation of predictors accurately at population level. In this research gap, the present research study aims to assess the predicators of $q S O F A$ and SIRS

\section{METHODS}

The study was a prospective besides with time-bound hospital-based observational study was conducted from Jan 2018 to Jun 2019 at Department of Emergency Medicine, PESIMSR, Kuppam, Andhra Pradesh. A total 150 adult patients presenting with clinical features of sepsis suspected cases were presenting to Emergency Room .All suspected cases were considered for the study relayed upon the primary admission over a period of 18 months IqSOFA and SIRS Criteria calculated].

\section{RESULTS}

Binary logistic regression was applied for estimation of area under curve and accurate prediction of sepsis cases at early stage, the results found that Increase in qSOFA Score $>=2$ was statistically significant AUC 0.82; CI 95\% 0.62-0.87; specificity $80 \%$ and sensitivity was $80.11 \%$. The association of 150 samples with support of Mechanical Ventilator, the descriptive statistics was used to know the significance of the correlation between q SOFA with respect to Mechanical Ventilator, results was found to be statistically correlated.

CONCLUSIONS

Summing of the results concludes that, both qSOFA and SIRS subjects were showed positively correlated with higher rate of life supporting treatment and directly proportional to number of hospital stay $t$ o reduce the morbidity and mortality. The research study coveted to predict the accurate infection and symptoms at early stage

KEYWORDS: qSOFA, SIRS, AUC, Organ dysfunction, GCS
\end{abstract}

Received: Oct 05, 2020; Accepted: Oct 25, 2020; Published: Dec 07, 2020; Paper Id.: IJMPSOCT20202

\section{INTRODUCTION}

Sepsis is a syndrome with multiple infection and manifestation in response clinical settings. As per the medical ethics , the 
infection is delirious and cause primary infection and incremental increased the medical emergency .The intervention of sepsis is largely depends on the treatment and mechanisms of patients managing with life supporting treatment .Many literature reviewed to addressed the mortality and morbidity at population level, sepsis is life threatened dysfunction and its is represented by an two points increase in the Sqfa assessment score. Disease predictors is very important for the clinician to draw accurate clinical decision about the exposed population. Some of the assessment would be encompasses to highlights the signs and symptoms. In this vein Qsofa Score is used to escalates the severity of the disease . Many literature cited worldwide to addresses the key issues of both (sqofa and SIRS) .Intervention remains ambiguous to manage the patients without severity assessment in Department of emergency. Accurate prediction method defines various characteristics on selected parameters, viz. respiratory rate, oxygen level, body temperature, heart rate and AVPUS score with maximum of twenty points . Clinically we used the following criteria, the subjects meet two or more of the following parameters, respiratory rate of the cases $>=22$ breaths per minutes, altered mental status and systolic blood pressure $<=100 \mathrm{~mm} / \mathrm{hg}$. Similarly in case of SIRS , the criteria would meet the followings criteria , temperature $<36$ degree centigrade or $>38$ degree centigrade, heart rate of subjects bears $>90$ beats per minute and RR $>20$ breaths per minutes. In Indian scenario ,very limited number of literature cited for addressing the research gap of estimation of predictors accurately at population level[18] . In this research gap, the present research study aims to extrapolate the predicators of qSOFA and SIRS

\section{METHODS}

The present study was done prospective basis with time-bound. Hospital-based observational study was conducted from Jan 2018 to Jun 2019 at Department of Emergency Medicine, PESIMSR, Kuppam, Andhra Pradesh. A total 150 adult patients presenting with clinical characteristics of Sepsis and shock and suspected cases were recruited at ED .All suspected cases were considered for the study relayed upon the primary admission over a period of 18 months [qSOFA and SIRS Criteria calculated].The following inclusion exclusion criteria was employed for recruitment of patients Inclusion Criteria; All consecutive adult patients aged between 18 to 59 years presenting to Emergency Room with suspected SEPSIS, Patients satisfy the criteria for sepsis and septic shock based on QSOFA and SIRS scores, Exclusion Criteria; Age less than 15years; Patients in whom there are technical difficulties in measuring parameters accurately and Patients presenting with a confounding diagnosis along with the primary diagnosis of Sepsis like Acute Coronary Syndrome, Diabetic Ketoacidosis, Burns, Trauma, Patients Requiring Immediate Surgical Intervention. All Patients were admitted in Emergency department with known suspected sepsis, it was assessed in accordance with Standard protocols and treating by the Physicians Discretions; parameters of q SOFA AND SIRS was calculated and tabulated.

\section{Ethical Issues}

An Institutional ethical Clarence was obtained from the Competent authority ,after obtaining IE we started the study at greatest accuracy . Patients selection and recruitment was done on the basis of standard operating protocol and regularity guidelines. Collected data was analyzed by using $\mathrm{R}$-statistical software .Logistic regression and Survival analysis was done for estimating the predictors of qSOFA and SIRS respectively. 
Results

Table 1.1: shows association of death \& discharge with sirs [n=150]

\begin{tabular}{|c|c|c|c|c|c|c|c|c|}
\hline \multirow{3}{*}{ SIRS } & \multicolumn{6}{|c|}{ Death \& Discharge } & \multicolumn{2}{|c|}{ Chi-square } \\
\hline & \multicolumn{2}{|c|}{ Discharged } & \multicolumn{2}{|c|}{$\begin{array}{c}\text { Death within } 24 \\
\text { Hrs }\end{array}$} & \multicolumn{2}{|c|}{$\begin{array}{c}\text { Death after } 24 \\
\text { Hrs }\end{array}$} & P-value & Results \\
\hline & $\mathbf{F}$ & $\%$ & $\mathbf{F}$ & $\%$ & $\mathbf{F}$ & $\%$ & \multirow{5}{*}{$* 0.028$} & \multirow{5}{*}{ Significant } \\
\hline 1 & 0 & $0 \%$ & 0 & $0 \%$ & 1 & $7.7 \%$ & & \\
\hline 2 & 16 & $14.8 \%$ & 6 & $20.7 \%$ & 0 & $0 \%$ & & \\
\hline 3 & 50 & $46.3 \%$ & 12 & $41.4 \%$ & 8 & $61.5 \%$ & & \\
\hline 4 & 42 & $38.9 \%$ & 11 & $37.9 \%$ & 4 & $30.7 \%$ & & \\
\hline
\end{tabular}

Above Table 1.1 shows that, the association of 150 samples with their SIRS criteria for likelihood of mortality and survivability, the descriptive statistics was used to test the significance $(\mathrm{p}<0.05)$ and explore any significant association between mortality \& discharge cases of SIRS score or criteria, results found that, there is significant difference was found between the SIRS criteria to control death and exponentially move survival rate of the sepsis cases accordingly ( $\mathrm{P}<0.05)$.

Table 1.2: Shows association of qSOFA with need of vasopressor [n=150]

\begin{tabular}{|c|c|c|c|c|c|c|c|c|c|c|}
\hline \multirow{3}{*}{$\begin{array}{l}\text { The need of } \\
\text { Vasopressor }\end{array}$} & \multicolumn{8}{|c|}{ q SOFA } & \multicolumn{2}{|c|}{ Chi-square } \\
\hline & \multicolumn{2}{|c|}{ 0 } & \multicolumn{2}{|c|}{1} & \multicolumn{2}{|c|}{2} & \multicolumn{2}{|c|}{3} & P-value & Results \\
\hline & $\mathbf{F}$ & $\%$ & $\mathbf{F}$ & $\%$ & $\mathbf{F}$ & $\%$ & $\mathbf{F}$ & $\%$ & \multirow{3}{*}{$* \mathrm{P}<0.001$} & \multirow{3}{*}{ Significant } \\
\hline 1 & 2 & 100 & 15 & 100 & 64 & 84 & 18 & 31.6 & & \\
\hline 2 & 0 & 0 & 0 & 0 & 12 & 15 & 39 & 68.4 & & \\
\hline
\end{tabular}

The above Table 1.2 shows that, the association of 150 samples with need of Vasopressor, the correlation was estimated by chi-square analysis. Study reveal that, there is positive association between qSOFA besides with need of Vasopressor and it was seen statistically significant at $\mathrm{P}<0.05$.

Table 1.3: Correlation between qSOFA with need of mechanical ventilator [n=150]

\begin{tabular}{|c|c|c|c|c|c|c|c|c|c|c|}
\hline \multirow{3}{*}{$\begin{array}{c}\text { Need of } \\
\text { Mechanical } \\
\text { Ventilator }\end{array}$} & \multicolumn{8}{|c|}{ q SOFA } & \multicolumn{2}{|c|}{ Chi square } \\
\hline & \multicolumn{2}{|r|}{$\mathbf{0}$} & \multicolumn{2}{|c|}{1} & \multicolumn{2}{|c|}{2} & \multicolumn{2}{|c|}{3} & P-value & Results \\
\hline & $\mathbf{F}$ & $\%$ & $\mathbf{F}$ & $\%$ & $\mathbf{F}$ & $\%$ & $\mathbf{F}$ & $\%$ & \multirow{3}{*}{$* \mathrm{P}<0.001$} & \multirow{3}{*}{ Significant } \\
\hline 1 & 2 & $100 \%$ & 15 & $100 \%$ & 61 & $80.3 \%$ & 30 & 52.6 & & \\
\hline 2 & 0 & $0 \%$ & 0 & $0 \%$ & 15 & $19.7 \%$ & 27 & 47.4 & & \\
\hline
\end{tabular}

The above Table 1.3 shows that, the association of 150 samples with support of Mechanical Ventilator, the paired and unpaired statistics was used to know the significance of the correlation between q SOFA with respect to Mechanical Ventilator, results was seen statistically significant at $\mathrm{P}<0.05$.

Table 1.4: shows association of $q$ SOFA with number of days ICU

\begin{tabular}{|c|c|c|c|c|c|c|c|c|c|c|}
\hline \multirow[t]{3}{*}{ No of ICU Days } & \multicolumn{8}{|c|}{ q SOFA } & \multicolumn{2}{|c|}{ Chi-square } \\
\hline & \multicolumn{2}{|r|}{$\mathbf{0}$} & \multicolumn{2}{|r|}{1} & \multicolumn{2}{|r|}{2} & \multicolumn{2}{|r|}{3} & P-value & Results \\
\hline & $\mathbf{F}$ & $\%$ & $\mathbf{F}$ & $\%$ & $\mathbf{F}$ & $\%$ & $\mathbf{F}$ & $\%$ & & Significant \\
\hline 1 & 1 & $50 \%$ & 7 & $46.7 \%$ & 8 & $10.5 \%$ & 28 & $49.1 \%$ & $* \mathrm{P}<0.001$ & \\
\hline
\end{tabular}




\begin{tabular}{|l|l|l|l|l|l|l|l|l|l|l|}
\hline 2 & 1 & $50 \%$ & 6 & $40.0 \%$ & 30 & $39.5 \%$ & 12 & $21.1 \%$ & & \\
\cline { 1 - 9 } & 0 & $0 \%$ & 2 & $13.3 \%$ & 38 & $50.0 \%$ & 17 & $29.8 \%$ & & \\
\hline
\end{tabular}

The above Table 1.4: shows that, the association of 150 samples correlation was done to explore the number of ICU Days and q SOFA, the paired t test and descriptive statistics was used or employed to any deviation of selected parameters, results was significantly associated between q SOFA in relation to number of ICU Days, and it was expressed statistically significant at $(\mathrm{P}<0.05)$.

Table 1.5: shows association of SIRS with Need of Vasopressor

\begin{tabular}{|c|c|c|c|c|c|c|c|c|c|c|}
\hline \multirow{3}{*}{$\begin{array}{l}\text { The need for } \\
\text { Vasopressor }\end{array}$} & \multicolumn{8}{|c|}{ SIRS } & \multicolumn{2}{|c|}{ Chi-square } \\
\hline & \multicolumn{2}{|r|}{1} & \multicolumn{2}{|r|}{2} & \multicolumn{2}{|r|}{3} & \multicolumn{2}{|r|}{4} & P-value & Results \\
\hline & $\mathbf{F}$ & $\%$ & $\mathbf{F}$ & $\%$ & $\mathbf{F}$ & $\%$ & $\mathbf{F}$ & $\%$ & \multirow{3}{*}{0.119} & \multirow{3}{*}{ Not Significant } \\
\hline 1 & 1 & $100 \%$ & 16 & $72.7 \%$ & 51 & $72.9 \%$ & 31 & 54.4 & & \\
\hline 2 & 0 & $0 \%$ & 16 & $27.3 \%$ & 19 & $27.1 \%$ & 26 & 45.6 & & \\
\hline
\end{tabular}

The above Table 1.5 shows that, the association of 150 samples with their Need of Vasopressor, chi-square analysis was used to determine the significance of the association between SIRS results was showed to be insignificant at ( $\mathrm{P}>0.05)$.

Table 1.6: shows association of SIRS with Need of Mechanical Ventilator

\begin{tabular}{|c|c|c|c|c|c|c|c|c|c|c|}
\hline \multirow{3}{*}{$\begin{array}{l}\text { Need for } \\
\text { Mechanical of } \\
\text { Ventilator }\end{array}$} & \multicolumn{4}{|c|}{ SIRS } & & & & & \multicolumn{2}{|c|}{ Chi-square } \\
\hline & \multicolumn{2}{|l|}{1} & \multicolumn{2}{|l|}{2} & \multicolumn{2}{|l|}{3} & \multicolumn{2}{|l|}{4} & P-value & Results \\
\hline & $\mathbf{F}$ & $\%$ & $\mathbf{F}$ & $\%$ & $\mathbf{F}$ & $\%$ & $\mathbf{F}$ & $\%$ & \multirow{3}{*}{0.122} & \multirow[t]{3}{*}{ Not Significant } \\
\hline 1 & 1 & $100 \%$ & 16 & 72.7 & 56 & 80.0 & 35 & 61.4 & & \\
\hline 2 & 0 & $0 \%$ & 6 & 27.3 & 14 & 20.0 & 22 & 38.6 & & \\
\hline
\end{tabular}

The above Table 1.6 shows that, the association of 150 samples with their Need Of Mechanical Ventilator, chisquare analysis was used to determine the significance of the association between SIRS with support of Mechanical Ventilator, it was recorded as significant at $(\mathrm{P}>0.05)$.

Table 1.7: shows association of SIRS with Number of ICU Days stay

\begin{tabular}{|c|c|c|c|c|c|c|c|c|c|c|}
\hline \multirow{3}{*}{$\begin{array}{l}\text { No of ICU } \\
\text { Days }\end{array}$} & \multicolumn{8}{|c|}{ SIRS } & \multicolumn{2}{|r|}{ Chi-square } \\
\hline & \multicolumn{2}{|r|}{1} & \multicolumn{2}{|r|}{2} & \multicolumn{2}{|r|}{3} & \multicolumn{2}{|r|}{4} & P-value & Results \\
\hline & $\mathbf{F}$ & $\%$ & $\mathbf{F}$ & $\%$ & $\mathbf{F}$ & $\%$ & $\mathbf{F}$ & $\%$ & \multirow{4}{*}{0.486} & \multirow[t]{4}{*}{ not Significant } \\
\hline 1 & 0 & $0 \%$ & 7 & $31.8 \%$ & 18 & $25.7 \%$ & 19 & $33.3 \%$ & & \\
\hline 2 & 1 & $100 \%$ & 9 & $40.9 \%$ & 25 & $35.7 \%$ & 14 & $24.6 \%$ & & \\
\hline 3 & 0 & $0 \%$ & 6 & $27.3 \%$ & 27 & $38.6 \%$ & 24 & $42.1 \%$ & & \\
\hline
\end{tabular}

The above Table 1.7 shows that, the association of 150 samples of No of ICU Days regressed with SIRS criteria, the chi-square analysis was used to determine the significance of the association between SIRS and No of ICU Days, results showed to be insignificant at $\mathrm{P}>0.05$. 


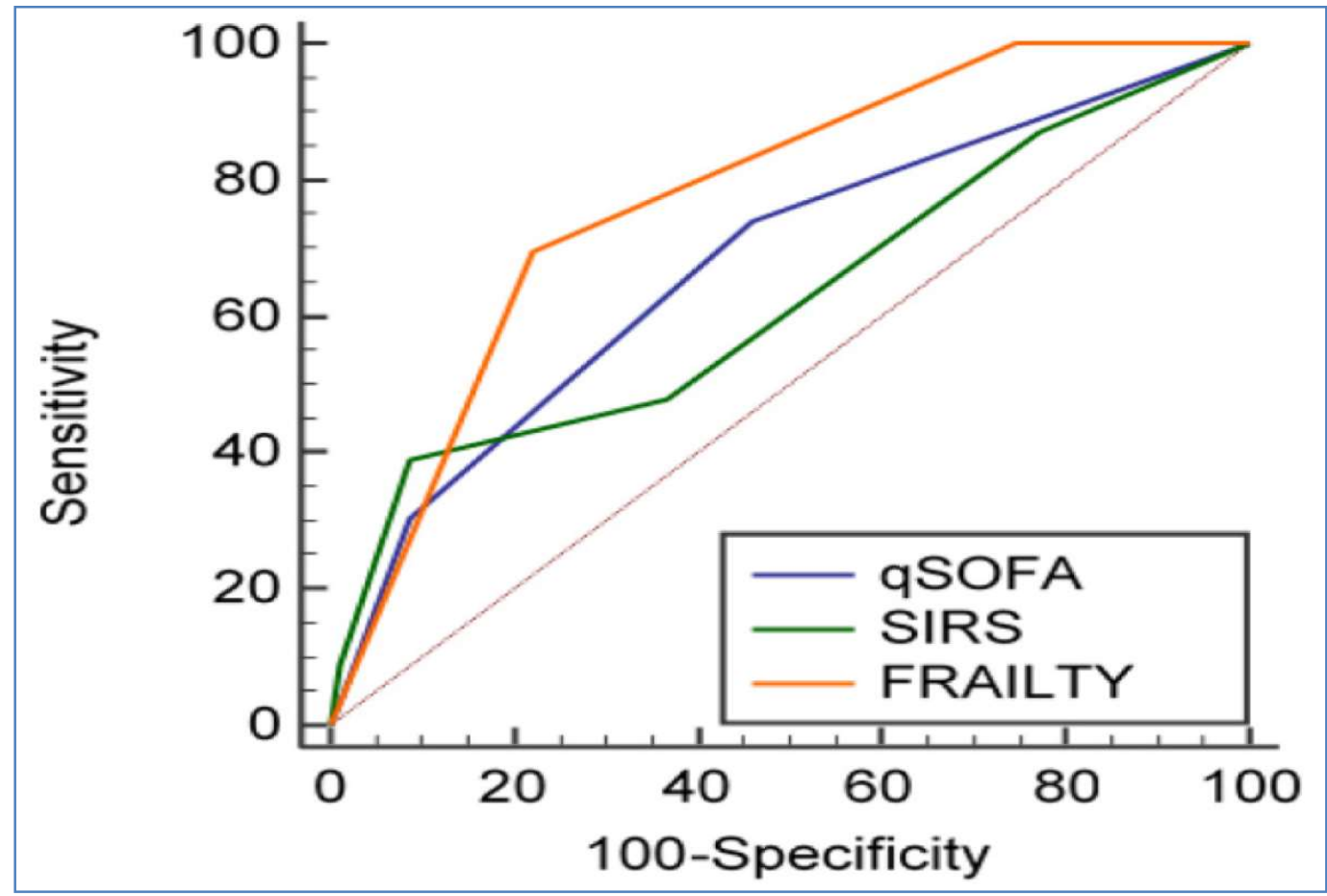

Figure 1.1: Kaplan Meir curve of qSOFA \& SIRS

Fig 1.1 depicted that, qSOFA \& SIRS shows significant difference was seen in the control of mortality rate, the cases were screened at early stage, which is more benefited to estimate the likelihood ration and hazard function of sepsis and sepsis shock patients. Both the variables of qSOFA \& SIRS were shows better results for diagnosing the cases in association with many clinical attributes

Table 1.8: Area under curve of Increase in SOFA and SIRS

\begin{tabular}{|l|l|l|l|l|}
\hline & \multicolumn{1}{|c|}{$\begin{array}{c}\text { AUC } \\
\text { ROC }\end{array}$} & \multicolumn{1}{|c|}{ CI-95\% } & \multicolumn{1}{c|}{ Sensitivity (\%) } & \multicolumn{1}{|c|}{ Specificity (\%) } \\
\hline $\begin{array}{l}\text { Increase in qSOFA } \\
\text { Score }>=2\end{array}$ & 0.82 & $0.62-0.87$ & 80.11 & 80 \\
\hline SIRS $>=2$ & 0.68 & $0.52-0.691$ & 91.25 & 23 \\
\hline qSOFA $>=2$ & 0.71 & $0.68-0.74$ & 64.88 & 40.44 \\
\hline Lactate $>=2 \mathrm{mmol} / \mathrm{L}$ & 0.45 & $0.40-0.48$ & 67.42 & 76.85 \\
\hline
\end{tabular}

Table 1.8 shows, Binary logistic regression was applied for estimation of area under curve and accurate prediction of sepsis cases at early stage, the results found that Increase in qSOFA Score $>=2$ was statistically significant AUC 0.82 ; CI 95\% 0.62-0.87; specificity $80 \%$ and sensitivity was $80.11 \%$.

\section{DISCUSSIONS}

The study shown to be addressed the various predictors of qSOFA and SIRS criteria driven by the SOP .The outcomes Were seen mortality rate and ICU stay cases, it was regressed with structured score of the various components on both qSOFA and SIRS criteria. We have seen qSOFA shows significantly better than SIRS score for predicting unobservable components of disease. The ICU free days was representing factor to freeze the ventilator free days life supports, if any organ dysfunction free days were correlated structured score and it was statistically modelled with survival patrimonial 
methods [2-3].The study was found that, the increase level of SOFA score is $>=2$ is covered better expression [AUC 0.82 ; CI 95\% 0.52-0.96 ; sensitivity $80.11 \%$ and specificity $80.0 \%$.In case of SIRS score $>=2$ AUC was 0.68 CI $95 \% 0.68$ 0.74 ; sensitivity 91.25 with fewer value of specificity $40.44 \%$ ]. Mean while lactate level was fall on reference range $\mathrm{p}<0.01$ [8-9].Although, intervention could not be precluded that present study, not big enough to reveal marginal differences in such clinical outcomes, another plausible explanation is quoted on realistic approach , qSOFA is not shown a significantly accounted any signs of organ, renal and hepatic failure . In our results seem to be justify the concern qSOFA mortality, it may be less sensitive rather than SIRS criteria .For the sake of prediction, present predicting parameters shows clinical deterioration in patients at risk of sepsis considering with several clinical and serological attributes out of 150 samples with their Need of Vasopressor, SIRS Vasopressor ( $\mathrm{P}>0.05)$. The present research paper revealed that, the ICU days stay in hospital shows in significant, showed significance of the association between SIRS with their number of ICU Days and it was found to be insignificant at $(\mathrm{P}>0.05)$. However, a systematic and practical approach concludes that, the SIRS criteria is significantly decline mortality rate with Hazard ratio 3.62 .Approach is inevitable as compared with qSOFA score And it was established and validated in prognostic tools for hospital death among patients with suspected infection of sepsis, while SIRS criteria is useful tool for treating sepsis

\section{CONCLUSIONS}

The study concludes that, the Department of Emergency with admitted and suspected cases, the SIRS as compared to qSOFA patients were positively correlated higher incidence of life support treatment and hospital stay. SIRS and qSOFA criteria is significantly more accurate for predicting an early established infection of sepsis.

\section{REFERENCES}

1. Singer M, Deutschman CS, Seymour CW, Shankar-Hari M, Annane D, Bauer M, et al. The Third International Consensus Definitions for Sepsis and Septic Shock (Sepsis-3). Jama-J Am Med Assoc. 2016;315(8):801-10. WOS:000370700500015. pmid:26903338Levy MM, Fink MP, Marshall JC, Abraham E, Angus D, Cook D, et al. 2001 SCCM/ESICM/ACCP/ATS/SIS International Sepsis Definitions Conference. Crit Care Med. 2003;31(4):1250-6. Epub 2003/04/12. pmid:12682500.

2. Bone RC, Balk RA, Cerra FB, Dellinger RP, Fein AM, Knaus WA, et al. Definitions for sepsis and organ failure and guidelines for the use of innovative therapies in sepsis. The ACCP/SCCM Consensus Conference Committee. American College of Chest Physicians/Society of Critical Care Medicine. Chest. 1992;101(6):1644-55. Epub 1992/06/01. S0012-3692(16)38415-X [pii]. pmid:1303622.

3. Seymour CW, Liu VX, Iwashyna TJ. Assessment of Clinical Criteria for Sepsis: For the Third International Consensus Definitions for Sepsis and Septic Shock (Sepsis-3) (vol 315, pg 762, 2016). Jama-J Am Med Assoc. 2016;315(20):2237-. WOS:000376343000031.

4. Simpson SQ. New Sepsis Criteria: A Change We Should Not Make. Chest. 2016;149(5):1117-8. Epub 2016/03/02. S00123692(16)41523-0 [pii]. pmid:26927525.

5. Carneiro AH, Povoa P, Gomes JA. Dear Sepsis-3, we are sorry to say that we don't like you. Rev Bras Ter Intensiva. 2017;29(1):4-8. Epub 2017/04/27. S0103-507X2017000100004 [pii] pmid:28444066; PubMed Central PMCID: PMC5385979.

6. Goulden R, Hoyle MC, Monis J, Railton D, Riley V, Martin P, et al. qSOFA, SIRS and NEWS for predicting inhospital mortality and ICU admission in emergency admissions treated as sepsis. Emerg Med J. 2018;35(6):345-9. Epub 2018/02/23. emermed-2017-207120 [pii] pmid:29467173. 
7. Askim A, Moser F, Gustad LT, Stene H, Gundersen M, Asvold BO, et al. Poor performance of quick-SOFA (qSOFA) score in predicting severe sepsis and mortality - a prospective study of patients admitted with infection to the emergency department. Scand J Trauma Resusc Emerg Med. 2017;25(1):56. Epub 2017/06/11. [pii]. pmid:28599661; PubMed Central PMCID: PMC5466747.

8. Canet E, Taylor DM, Khor R, Krishnan V, Bellomo R. qSOFA as predictor of mortality and prolonged ICU admission in Emergency Department patients with suspected infection. J Crit Care. 2018;48:118-23. Epub 2018/09/04. S08839441(18)30768-8 [pii] pmid:30176527.

9. Hwang SY, Jo IJ, Lee SU, Lee TR, Yoon H, Cha WC, et al. Low Accuracy of Positive qSOFA Criteria for Predicting 28-Day Mortality in Critically Ill Septic Patients During the Early Period After Emergency Department Presentation. Ann Emerg Med. 2018;71(1):1-9 e2. Epub 2017/07/04. S0196-0644(17)30658-3 [pii] pmid:28669551.

10. Royal College of Physicians. National Early Warning Score (NEWS): Standardising the assessment of acute illness severity in the NHS. Report of a working party. London: RCP; 2012.

11. Kivipuro M, Tirkkonen J, Kontula T, Solin J, Kalliomaki J, Pauniaho SL, et al. National early warning score (NEWS) in a Finnish multidisciplinary emergency department and direct vs. late admission to intensive care. Resuscitation. 2018;128:1649. Epub 2018/05/19. S0300-9572(18)30231-4 [pii] pmid:29775642.

12. .Hoikka M, Silfvast T, Ala-Kokko TI. Does the prehospital National Early Warning Score predict the short-term mortality of unselected emergency patients? Scand J Trauma Resusc Emerg Med. 2018;26(1):48. Epub 2018/06/09. [pii]. pmid:29880018; PubMed Central PMCID: PMC5992854.

13. Alexander RH, Proctor HJ, American College of Surgeons, Committee on Trauma. Advanced Trauma Life Support Program For Physicians: ATLS. 5th ed. Chicago, IL: American College of Surgeons; 1993.

14. Pedersen AB, Mikkelsen EM, Cronin-Fenton D, Kristensen NR, Pham TM, Pedersen L, et al. Missing data and multiple imputation in clinical epidemiological research. Clin Epidemiol. 2017;9:157-66. Epub 2017/03/30. [pii]. pmid:28352203; PubMed Central PMCID: PMC5358992.

15. .Jo S, Yoon J, Lee JB, Jin Y, Jeong T, Park B. Predictive value of the National Early Warning Score-Lactate for mortality and the need for critical care among general emergency department patients. J Crit Care. 2016;36:60-8. Epub 2016/11/05. S08839441(16)30138-1 [pii] pmid:27546749.

16. Shaw J, Fothergill RT, Clark S, Moore F. Can the prehospital National Early Warning Score identify patients most at risk from subsequent deterioration? Emerg Med J. 2017. Epub 2017/05/16. emermed-2016-206115 [pii] pmid:28501815.

17. .Sbiti-Rohr D, Kutz A, Christ-Crain M, Thomann R, Zimmerli W, Hoess C, et al. The National Early Warning Score (NEWS) for outcome prediction in emergency department patients with community-acquired pneumonia: results from a 6-year prospective cohort study. BMJ Open. 2016;6(9):e011021. Epub 2016/09/30. bmjopen-2015-011021 [pii] pmid:27683509; PubMed Central PMCID: PMC5051330.

18. . Bilben B, Grandal L, Sovik S. National Early Warning Score (NEWS) as an emergency department predictor of disease severity and 90-day survival in the acutely dyspneic patient-a prospective observational study. Scand J Trauma Resusc Emerg Med. 2016;24:80. Epub 2016/06/03. [pii]. pmid:27250249; PubMed Central PMCID: PMC4890514.

19. Corfield AR, Lees F, Zealley I, Houston G, Dickie S, Ward K, et al. Utility of a single early warning score in patients with sepsis in the emergency department. Emerg Med J. 2014;31(6):482-7. Epub 2013/03/12. emermed-2012-202186 [pii] pmid:23475607.

20. Gill MR, Reiley DG, Green SM. Interrater reliability of Glasgow Coma Scale scores in the emergency department. Ann Emerg 
Med. 2004;43(2):215-23. Epub 2004/01/30. S019606440300814X [pii]. pmid:14747811.

21. OUTTAR, FAHIMA, et al. "THE INTERACTION OF L5 LARVAE OF LOCUSTA MIGRATORIA (LINNAEUS, 1758)(OEDIPODINAE, ACRIDIDAE) WITH BIOBESTICIDES." (2014).

22. Semler MW, Stover DG, Copland AP, Hong G, Johnson MJ, Kriss MS, et al. Flash mob research: a single-day, multicenter, resident-directed study of respiratory rate. Chest. 2013;143(6):1740-4. Epub 2012/12/01. S0012-3692(13)60406-7 [pii] pmid:23197319; PubMed Central PMCID: PMC3747725.

23. Sjoding $M W$, Luo K, Miller MA, Iwashyna TJ. When do confounding by indication and inadequate risk adjustment bias critical care studies? A simulation study. Crit Care. 2015;19:195. Epub 2015/05/01. [pii]. pmid:25925165; PubMed Central PMCID: PMC4432515.

24. Cretikos MA, Bellomo R, Hillman K, Chen J, Finfer S, Flabouris A. Respiratory rate: the neglected vital sign. Med J Aust. 2008;188(11):657-9. Epub 2008/06/03. cre11027_fm [pii]. pmid:18513176.

25. Akinsola, V. O., and T. O. Oluyo. "Mathematical model of the complications and control of diabetes mellitus." Int $J$ Math Comput Appl Res 4.5 (2014): 1-14.

26. Asayama K, Aikawa N. Evaluation of systemic inflammatory response syndrome criteria as a predictor of mortality in emergency patients transported by ambulance. Keio Journal of Medicine. 1998;47(1):19-27. pmid:9560528.

27. Jones GR, Lowes JA. The systemic inflammatory response syndrome as a predictor of bacteraemia and outcome from sepsis. Qjm. 1996;89(7):515-22. pmid:8759492.

28. Park HK, Kim WY, Kim MC, Jung W, Ko BS. Quick sequential organ failure assessment compared to systemic inflammatory response syndrome for predicting sepsis in emergency department. J Crit Care. 2017;42:12-7. Epub 2017/06/26. S08839441(17)30395-7 [pii] pmid:28647650.

29. ALWAN, DR ZAINAB ABDULL MAJEED, and DR MAZIN MOHAMMAD JAWAD AL-MUSSAWY. "A STUDY OF MORTALITY AMONG UNDER-FIVE CHILDREN IN BASRAH-2014." International Journal of Medicine and Pharmaceutical Science (IJMPS) 9.4, Aug 2019, 7-22

30. Simpson SQ, City K. New Sepsis Criteria A Change We Should Not Make. Chest. 2016;149(5):1117-8. WOS:000375487600007. pmid:26927525

31. Sprung CL, Schein RMH, Balk RA. The new sepsis consensus definitions: the good, the bad and the ugly. Intens Care Med. 2016;42(12):2024-6. WOS:000387846500024. pmid:27815588 